\title{
Phytobiomes are compositionally nested from the ground up
}

\author{
Anthony S Amend Corresp., 1 , Gerald M Cobian ${ }^{1}$, Aki J Laruson ${ }^{2}$, Kristina Remple ${ }^{3}$, Sarah J Tucker ${ }^{4,5}$, Kirsten E \\ Poff ${ }^{6}$, Carmen Antaky ${ }^{7}$, Andre Boraks ${ }^{1}$, Casey A Jones ${ }^{1}$, Donna Kuehu ${ }^{8}$, Becca R Lensing ${ }^{4,9}$, Mersedeh \\ Pejhanmehr ${ }^{1}$, Daniel T Richardson ${ }^{7}$, Paul P Riley ${ }^{7}$ \\ 1 Department of Botany, University of Hawaii at Manoa, Honolulu, HI, United States \\ 2 Department of Biology, University of Hawaii at Manoa, Honolulu, HI, United States \\ 3 Department of Oceanography, University of Hawaii at Manoa, Honolulu, HI, United States \\ 4 Marine Biology Program, University of Hawaii at Manoa, Honolulu, HI, United States \\ 5 Hawaii Institute of Marine Biology, University of Hawaii at Manoa, Honolulu, HI, United States \\ 6 Plant and Environmental Protection Services, University of Hawaii at Manoa, Honolulu, HI, United States \\ 7 Department of Natural Resources and Environmental Management, University of Hawaii at Manoa, Honolulu, HI, United States \\ 8 \\ 9 Microbiology, University of Hawaii at Manoa, Honolulu, Hawaii, United States \\ Corresponding Author: Anthony S Amend \\ Email address: amend@hawaii.edu
}

Plant-associated microbes are critical players in host health, fitness and productivity. Despite microbes' importance in plants, seeds are mostly sterile, and most plant microbes are recruited from an environmental pool. Surprisingly little is known about the processes that govern how environmental microbes assemble on plants in nature. In this study we examine how bacteria are distributed across plant parts, and how these distributions interact with spatial gradients. We sequenced amplicons of bacteria from the surfaces of six plant parts and adjacent soil of Scaevola taccada, a common beach shrub, along a 60 km transect spanning O'ahu island's windward coast, as well as within a single intensivelysampled site. Bacteria are more strongly partitioned by plant part as compared with location. Within S. taccada plants, microbial communities are highly nested: soil and rhizosphere communities contain much of the diversity found elsewhere, whereas reproductive parts fall at the bottom of the nestedness hierarchy. Nestedness patterns suggest either that microbes follow a source/sink gradient from the ground up, or else that assembly processes correlate with other traits, such as tissue persistence, that are vertically stratified. Our work shines light on the origins and determinants of plantassociated microbes across plant and landscape scales. 


\section{Phytobiomes are compositionally nested from the} 3 ground up

4

Anthony S. Amend ${ }^{1}$, Gerald M. Cobian ${ }^{1}$, Áki J. Láruson ${ }^{2}$, Kristina Remple ${ }^{3}$, Sarah J. Tucker $^{4,8}$, Kirsten E. Poff ${ }^{5}$, Carmen Antaky ${ }^{7}$, Andre Boraks ${ }^{1}$, Casey A. Jones ${ }^{1}$, Donna Kuehu $^{9}$, Becca R. Lensing ${ }^{4,6}$, Mersedeh Pejhanmehr ${ }^{1}$, Daniel Richardson ${ }^{7}$, Paul P. Riley ${ }^{7}$,

${ }^{1}$ Department of Botany, University of Hawai'i at Mānoa, Honolulu, HI, USA 2Department of Biology, University of Hawai'i at Mānoa, Honolulu, HI, USA ${ }^{3}$ Department of Oceanography, University of Hawai'i at Mānoa, Honolulu, HI, USA ${ }^{4}$ Marine Biology Program, University of Hawai'i at Mānoa, Honolulu, HI, USA ${ }^{5}$ Plant and Environmental Protection Sciences, University of Hawai'i at Mānoa, Honolulu, HI, USA ${ }^{6}$ Microbiology, University of Hawai'i at Mānoa, Honolulu, HI, USA ${ }^{7}$ Department of Natural Resources and Environmental Management, University of Hawai'i at Mānoa, Honolulu, HI, USA ${ }^{8}$ Hawai'i Institute of Marine Biology, Kaneohe, HI, USA ${ }^{9}$ Department of Molecular Biosciences and Bioengineering

Corresponding Author:

Anthony S Amend, Department of Botany, University of Hawaii Manoa, 3190 Maile Way, Honolulu, HI 96822 U.S.A.

Email: Amend@hawaii.edu

\section{Abstract}

Plant-associated microbes are critical players in host health, fitness and productivity.

Despite microbes' importance in plants, seeds are mostly sterile, and most plant microbes are

recruited from an environmental pool. Surprisingly little is known about the processes that govern how environmental microbes assemble on plants in nature. In this study we examine how bacteria are distributed across plant parts, and how these distributions interact with spatial gradients. We sequenced amplicons of bacteria from the surfaces of six plant parts and adjacent soil of Scaevola taccada, a common beach shrub, along a $60 \mathrm{~km}$ transect spanning O'ahu island's windward coast, as well as within a single intensively-sampled site. Bacteria are more 
44

strongly partitioned by plant part as compared with location. Within S. taccada plants, microbial communities are highly nested: soil and rhizosphere communities contain much of the diversity

found elsewhere, whereas reproductive parts fall at the bottom of the nestedness hierarchy.

Nestedness patterns suggest either that microbes follow a source/sink gradient from the ground up, or else that assembly processes correlate with other traits, such as tissue persistence, that are vertically stratified. Our work shines light on the origins and determinants of plant-associated microbes across plant and landscape scales.

\section{Introduction}

Many of what we formerly considered "plant" traits we now know to be the direct or indirect result of a consortium of microbial species that colonize the inside and outside of plant tissues. Known as the phytobiome, these microscopic organisms from throughout the tree of life play critical roles in plant chemistry, health, fitness and phenology (Glick, 2014; Bulgarelli et al., 2015; Panke-Buisse et al., 2015; Hacquard et - al., 2015). Given microbes' central role in plant health, it is remarkable that most microbes are not inherited by birthright (like chloroplasts or mitochondria). Instead, most hosts emerge physically decoupled from their microbiomes, which are accumulated from the surrounding environment (Hodgson et al., 2014). This process may convey some advantages, as it enables a population to adapt to a local habitat more quickly than would be possible relying on the comparatively slow process of evolution (Lau \& Lennon, 2012). For this reason, a plant's location can be a strong determinant of phytobiome composition (O'Rorke et al., 2015). However, microbial composition can be conserved within plant parts across multiple host species and environments (Lundberg et al., 2012; Bodenhausen, Horton \& Bergelson, 2013; Ottesen et al., 2013; Lambais, 
62 Lucheta \& Crowley, 2014; Leff et al., 2015; Laforest-Lapointe, Messier \& Kembel, 2016;

63 Müller et al., 2016). Two leaves, though oceans apart, might nevertheless recruit a

64 similar consortia of microbes.

65 While researchers have expended considerable effort to study the assembly 66 dynamics driving phytobiome structure and diversity, we have yet to uncover from

67 where these microbes derive and how the relative contribution of spatial factors and 68 plant part governs the microbial assembly on plants. Here, we examined how two 69 factors: plant part identity and geographic distance, partition surface microbial 70 communities. We chose these variables because they represent strongly deterministic 71 and stochastic processes respectively, and because they are reasonably easy to isolate 72 on a volcanic island when aspect and elevation are held constant.

Factors contributing to differences among plant parts are highly deterministic and

74 form microhabitats that vary considerably at small spatial scales. Rhizospheres, for 75 example, combine physiochemical properties of soils with nutrient and moisture inputs 76 from plants (Fitzpatrick et al., 2018), whereas leaf surfaces can be hydroscopic and 77 nutrient poor (Remus-Emsermann \& Schlechter, 2018). Nectar producing flowers, on 78 the other hand, often provide a sugar-rich, low water potential, acidic habitat (Aleklett, 79 Hart \& Shade, 2014). Tissue longevity might further differentiate plant microbes. Whereas stems may persist for the entire life of a plant, most other tissues have more

81 limited lifespans. In some species (i.e. Hibiscus trionum, the so-called flower-of-an82 hour), flowers are open for less than a single day, a seemingly short timeframe in which 83 to recruit and establish a resident microbiome. Distance, in contrast, serves as proxy for 84 dispersal limitation (Peay et al., 2012) or priority affects (Kennedy, Peay \& Bruns, 2009; 
85 Cadotte, Cardinale \& Oakley, 2012), which are stochastic environmental drivers

86 assuming that other environmental conditions are held constant.

Further, we sought to determine whether within-plant distributions of microbes

88

89

90

91

92 are consistent with microbial source sink dynamics. We hypothesized that soil and rhizosphere microbial communities serve as a reservoir for above-ground plant parts. By conceptualizing plant parts as nodes in a bipartite network we can determine whether microbial communities in ephermeral and late-emerging plant parts are compositionally nested within early-developing and long-lived plant parts, consistent with the hypothesis that a plant effectively inoculates itself from the ground up.

To address these questions, we examined how distance and plant part identity structure the surface bacteria of beach Naupaka, Scaevola taccada, a widespread littoral shrub native to Hawai'i and much of the tropics. Sampling at three scales (within plant, within site, and across island) we examine how distance and plant part shape phytobiomes, and make comparisons with adjacent soil communities that assemble independent of a biological host. Using a multivariate modeling framework, we determine the extent to which community variance is partitioned by site and by plant part. Finally, to gain insight into phytobiome source sink dynamics, we determine whether microbial communities are compositionally nested with respect to plant part. We find that communities appear to be more sensitive to within-plant location, than to site differences. We find, unsurprisingly, a split between below-ground and above-ground samples, and distinct community structure on vegetative and reproductive plant parts, suggesting that plant part function and longevity may contribute to these differences. Phytobiomes within plants are compositionally nested, 
108 and demonstrate hierarchical structuring consistent with expectations of soils as plant

109 microbial reservoirs.

110

111

112

113

114

115

116

117

118

119

120

121

122

123

124

125

126

127

128

129

130

131

132

\section{Materials \& Methods}

\section{Sampling}

We selected our plant species and sites to minimize environmental

heterogeneity. S. taccada is an evergreen shrub, native to Hawai $i$, which produces fruits and flowers across seasons. It is also one of the most common littoral plants on Oahu's East (windward) shore, enabling sampling at regular spatial intervals. The coastal habitat was selected because local climates at this elevation are minimally influenced by land topography, and because all coastlines are accessible to the public by virtue of state law. All samples were collected on January 26, 2017. A single $S$. taccada individual was sampled from each of 10 locations along the windward shore of O'ahu at $6 \mathrm{~km}$ intervals (Fig. 1). Generally, there were few individuals containing both reproductive parts (fruits and flowers) at a given site, and if more than one was present the sampled individual was selected haphazardly. Within the Kailua site, nine additional individuals were selected haphazardly within a $50 \mathrm{~m}^{2}$ plot. Plant locations were recorded with a Garmin Rhino GPS. A single mature, disease-symptom free leaf, flower, fruit, stem and axil was sampled by swabbing with a sterile cotton swab that had been moistened with an alkaline Tris extraction buffer (containing EDTA and KCL; comparable to Extract-N-Amp solution Sigma Aldrich, St. Louis). At two locations we were unable to locate and sample flowers. Root (rhizosphere) samples were collected by selecting an area of the root with diameter $0.5-1.7 \mathrm{~cm}$, and buried $2-10 \mathrm{~cm}$ below the surface. Soil was collected on swabs taken within $10 \mathrm{~cm}$ of the plant base, at a depth of 
$1332-5 \mathrm{~cm}$. Because soil was likely the most heterogeneous component of our study, bulk

134 soil samples were also collected for soil description; including soil taxonomy and $\mathrm{pH}$.

135 Finally, sterile swabs dipped in extraction solution were exposed to the air for

136 approximately 20 seconds as extraction negative controls. After sampling, swabs were

137 immersed in $200 \mu \mathrm{L}$ extraction buffer and stored in a cooler until DNA extraction later in

138 the day. Although soil is not technically a plant part, we refer to it as such when

139 differentiating sample types below.

140

141

142

143

144

145

146

147 148 buffer.

149

150

151

152

153

154

155

Nucleic Acid Extraction and Library Preparation

Swabs were incubated in $50 \mu \mathrm{L}$ of the extraction buffer at $65^{\circ} \mathrm{C}$ for 10 minutes and at $95^{\circ} \mathrm{C}$ for an additional 10 minutes. After brief centrifugation, swabs were removed from the buffer, and $200 \mu \mathrm{L}$ of $3 \%$ BSA was added to each sample. DNA extractions were purified and concentrated using a carboxylated paramagnetic bead solution. Briefly, $100 \mu \mathrm{L}$ of gDNA was mixed with $80 \mu \mathrm{L}$ of bead solution, immobilized with magnets, washed twice with $70 \%$ ethanol, and suspended in $30 \mu \mathrm{L}$ of $0.1 \times \mathrm{TE}$

\section{DNA library preparation and sequencing}

PCRs targeted the $\mathrm{v} 4$ region of the $16 \mathrm{~S}$ rRNA gene using the primers $515 \mathrm{f}$

(GTGCCAGCMGCCGCGGTAA) and 806r (GGACTACHVGGGTWTCTAAT)

with overhangs complementary to the 3 ' region of a construct containing dual $8 \mathrm{bp}$

indices and the Illumina i5 and i7 adaptors following the standard Illumina $16 \mathrm{~S}$

Metagenomic Sequencing Library Preparation protocol 
156 (https://support.illumina.com/content/dam/illumina-

157 support/documents/documentation/chemistry_documentation/16s/16s-metagenomic-

158 library-prep-guide-15044223-b.pdf ; Illumina, San Diego, CA), using KAPA3G plant

159 PCR kit reagents. Briefly the first PCR was carried out in a $25 \mu \mathrm{L}$ reaction consisting of

16025 cycles. Amplicons were diluted 1:10 and used as a template for the second "Index

161 PCR" in which sample-specific illumina indices and sequencing adapters were added

162 using an additional 8 cycles.

163 Negative PCR controls (extraction and field blanks), were added to the library

164 preparations. PCR products were purified and normalized to equimolar concentrations

165 using the just-a-plate 96 PCR Purification and Normalization Kit (Charm Biotech, San

166 Diego, California, USA). Normalized PCR products were pooled and sequenced at the

167 Hawai'i Institute of Marine Biology CORE Laboratory using the Illumina MiSeq V3, 600

168 cycle, paired-end protocol. PhiX (15\%) was added to the sequencing reaction to

169 increase template complexity. A region of the flow-cell was deemed defective after its

170 use, resulting in fewer high-confidence sequencing data than is typically recovered

171 using this technology. Sequence data were deposited to the SRA as PRJNA385181.

172

173 Data processing

174 Average reverse sequence quality scores declined to $<25$ after ca 150 bp and R2

175 sequences were, therefore, not further considered. Chimeras were detected and

176 removed from 16 S sequences using VSEARCH (Rognes et al., 2016). Sequences were

177 filtered by length (75 bp min) and quality score (mean score 25) and demultiplexed

178 within the QIIME environment (Caporaso et al., 2010). OTU binning at $97 \%$ identity and 
179 taxonomic assignments were conducted in QIIME's "open reference" workflow using 180 default parameters (Caporaso et al., 2010) and the Greengenes 13_8 reference 181 database. Taxa that were not assigned to bacteria (chloroplasts, and two mitochondria 182 sequences) were removed from datasets, as were OTUs represented by ten or fewer 183 sequences. None of the extraction or field negatives produced sequence data. sampled to 1,000 reads per sample, a cutoff that included the majority of samples. Although there is no consensus about how best to treat uneven sampling depth, downsampling to a common depth is generally robust for multivariate comparisons of community compositions (Weiss et al., 2017). Eighty-five samples containing greater than 1,000 reads were retained for subsequent analysis.

\section{Data Analyses}

To determine which factors (site and/or plant part) predicted community composition, binary Jaccard distances were used in a single PERMANOVA model 194 (function "adonis" in the vegan package (Oksanen et al., 2013)) considering marginal values of both factors and their interactions. In order to balance the number of samples among sites, a single individual plant was selected for the Kailua site. This analysis was repeated, including all samples from the Kailua site with qualitatively similar results. Because the analysis can be sensitive to dispersion of beta-diversity values, these were evaluated separately for plant parts. Following a globally significant RDA analysis showing that community dissimilarity was predicted by site, plant part and their 
201 interaction, a variance partitioning approach was used to determine the proportion of 202 variance explained by each.

203 To address whether soil or plant parts might serve as a microbial reservoir for 204 self-inoculation, we used two measures of nestedness, both of which indicate the extent 205 to which OTUs present in species-poorer plant parts are contained in those with higher 206 species richness. A bipartite matrix was calculated by summing all reads within each 207 plant part and then downsampling to the lowest sample sum. We calculate the 208 nestedness temperature (Atmar \& Patterson, 1993), a popular, though older, method 209 calculating nestedness as a range from 0 (perfectly nested) to 100 (perfectly random)

210 based on hierarchical entropy order and presence absence data. We also calculated 211 nestedness based on overlap and decreasing fill (NODF; Almeida-Neto et al., 2008) 212 scaled from 0 to 1 . Both were compared with a distribution of randomized null 213 communities generated using the quasiswap method in vegan. Differences in 214 community membership among habitats were decomposed into nestedness and 215 turnover components (Baselga \& Orme, 2012) as implemented in the nestedbetajac 216 function in vegan.

217 The extent to which certain plant parts "select for" microbes, was calculated 218 using the network-wide $\mathrm{H} 2$ index (Blüthgen, Menzel \& Blüthgen, 2006), which returns a 219 value from 0 (generalized) to 1 (specialized) based on potential associations given OTU 220 abundance totals. Significant deviations from null expectations were quantified using a 221 distribution of null community matrixes calculated using the quantitative r2dtable method 222 in vegan in which marginal totals are maintained. We calculated the related d' statistic 223 (Blüthgen, Menzel \& Blüthgen, 2006) to assess selectivity of individual plant parts. 
To test for dissimilarity by distance patterns, binary Jaccard community

225

226

227

228

229

230

231

232

233

234

235

236

237

dissimilarities were compared with geographic distances between samples using Mantel correlations (tests using Bray Curtis indices were qualitatively identical). So that the intensively sampled Kailua site did not skew detected spatial structure, we randomly selected a single Kailua individual for analysis (Mantel correlations including all samples showed similar effect sizes, except for above ground plant parts, which no longer showed a significant pattern; Table S2).

Indicator species analysis was calculated using the indicspecies package (De Caceres \& Jansen, 2016) on single groups (multi-group combinations were suppressed due to the high number of OTUs).

\section{Results}

Sequencing results

Illumina sequencing of the V4 region of bacteria $16 \mathrm{~S}$ gene generated $15,354,523$ reads. Following demultimplexing, quality score filtering and chimera detection $8,901,385$ bacteria reads remained. Removal of OTUs identified as chloroplasts and mitochondria, and OTUs present in read abundances $<10$ resulted in 4,643,809 reads and 2,192 bacteria OTUs retained for subsequent analysis.

\section{Specialization and nestedness of habitats}

Bacteria were significantly more nested than null expectations (Table 1; Fig. 1) and nestedness contributed $9 \%$ of total between-sample dissimilarity. Nestedness hierarchy followed the vertical structure of the plant: below-ground samples contained the highest species richness, above-ground vegetative structures were intermediate, and reproductive structures were lowest in the hierarchy (Fig. 2). 
Microbes were significantly specialized on particular plant parts. We examine the

250 degree and nature of specialization across plant parts using a bipartite network

251 architecture index, and also within plant part using an indicator species analysis.

252 Network-wide degrees of specialization were high and 762 "indicator species" were

253 statistically associated with plant parts (Table S3). The d' statistic, which measures

254 degree of specialization for individual habitats, showed that soil and rhizosphere were

255 the most specialized parts.

256

257 Plant part and abiotic drivers of community composition

258

A PERMANOVA model demonstrated that both plant part and location shape $S$.

taccada phytobiomes (Table 2), but that there was no interaction between those terms.

260

Further examination of community partitioning demonstrates that plant part is a stronger

determinant of bacteria community than location. Partitioning of variance, based on

262

RDA analysis, demonstrated differences in the relative importance contributed by these

two variables. Plant part accounted for $88 \%$ of the explained variance (RDA, $D F=50$,

$F=1.33, P=0.043)$, although residual variance accounted for $81 \%$ of the total, suggesting

that other unmeasured variables may be more predictive of community composition.

NMDS ordination (Fig. 3) demonstrates that bacteria communities assorted into

267 three principle groups associated with plant parts: belowground (soil and rhizosphere),

268 mid-plant vegetative (stem and axil), and reproductive (fruit and flower). Leaf samples

269 are spread among the other above-ground plant parts. Dispersion of bacteria beta

270 diversity (bacteria betadispersion ANOVA, $D F=6, P=0.08$; Fig. $S 1$ ) did not differ

271 significantly between any sample types, suggesting that results of the PERMANOVA 
272 analysis reflect differences in multidimensional community "location" rather than spread.

273 Bacteria were strongly partitioned at the order level by plant parts (Fig. 4). Bacillales

274 were ubiquitous and abundant in soil and leaf samples, whereas Rhizobiales and

275 Actinomycetales were abundant across root and vegetative plant parts.

276 While site location was a strong predictor of compositional differences, tests of

277 dissimilarity by distance for microbial community compositions showed mixed results.

278 There was a strong distance-decay relationship for below-ground samples and the

279 relationship for above-ground plant parts and all samples was weaker, though

280 significant (Table 3). Although geographic distance was generally a poor predictor of

281 microbial composition, site location strongly impacted community composition (Table 2).

282 This may be due to a deterministic influence of environmental variables that were not

283 accounted for in our study, including the influence of the surrounding vegetation.

285 Discussion

Distribution of OTUs across the plant

We show that the surface phytobiome composition of $S$. taccada is strongly

shaped by plant part. Both community similarity and richness patterns are structured by plant parts: stem, axil, and reproductive parts were most similar to each other, rhizosphere samples were most similar to soil samples, and leaves were allied with above-ground parts more generally. Segregation of microbial communities by plant part

292 (Junker et al., 2011; Ottesen et al., 2013; Junker \& Keller, 2015) and even withinindividual part location (Leff et al., 2015) has been reported for bacteria previously. Notably, Leff and colleagues demonstrated that both fungi and bacteria are partitioned 
296

297 298 299 300 301 302 303 304 305 306 307

317 airborne bacteria), with nestedness patterns resulting from ordered extinctions, could be 318 tested via experimental manipulations.

examining differences among plant parts within a network context, however, we gain insight into the potential sources and sinks of plant microbes.

Compositional differences between samples might be attributed to both species replacement and nestedness components, and the relative contributions of these variables can suggest causal mechanisms (Baselga, 2010). High turnover typically suggests stochastic assembly processes, whereas nestedness is more characteristic of deterministic factors such as environmental filtering (Si et al., 2016). We found that $9 \%$ of compositional differences was due to nestedness, a number that is consistent with the global mean of $0.093 \pm 0.054(S D)$, calculated in a recent meta-analysis of 99 studies, including microbes (Soininen et al., 2017). In contrast, the proportion of betadiversity explained by turnover, $84 \%$, was significantly higher than the global mean of $53 \% \pm 18.4(S D)$

We show that soil may be an important source for plant-surface microbiomes, including above-ground parts. Our analysis demonstrates that plant microbes are nested with respect to plant parts, that nestedness accounts for a large proportion of the among-sample diversity, and that below-ground parts (soil and rhizosphere) are at the top of the hierarchy. Even putative "soil" dwelling microbes, such as Bacillales, are found throughout the plant. These results suggest that soils may serve as an important source for plant-surface microbes, either through initial inoculation as the plant emerges from the ground, or repeated introduction via wind and water dispersal. An alternative hypothesis, that soils and plants could both be sinks from an alternative source (such as airborne bacteria), with nestedness patterns resulting from ordered extinctions, could be tested via experimental manipulations. 
Several other studies have noted nestedness patterns in other microbial

systems, including mycorrhizal tree islands displaying strong species area relationships

321 (Peay, Bruns \& Kennedy, 2007), and mouse guts whose bacterial diversity decreases,

322 orderly, over generations (Sonnenburg et al., 2016). Notably, bacteria phyla from 97

323 independent studies spanning diverse geography and habitat were significantly nested

324 (nestedness decreased with taxonomic rank; Thompson et al., 2017). Although they did 325

not consider plant parts per se, they also found significant nestedness patterning among plant samples, with rhizosphere being the most species rich category, followed by plant

327

328

329

330

331

332

333

334

335

336

337

338

339

340

341

surfaces, and internal plant tissues.

Despite nestedness patterns overall, each plant part contained a distinct subset of indicator bacteria that were not shared. These patterns suggest that distinct assembly processes may govern different plant parts. Pollinators, for example, are known to be effective vectors for microbes found in nectar and other plant parts (Herrera et al., 2010; Aleklett, Hart \& Shade, 2014), although nectar yeasts are the best known examples. Less is known about the origins or mechanisms of inoculation of other plant parts. Factors other than physiochemical plant traits also likely play a role in shaping phytobiomes. The strong division between below- and above-ground communities, for example, may result from dispersal limitation in addition to climatic differences.

Furthermore, plant part longevity may play a role in compositional differences. Flowers and fruits, the plant parts with lowest species richness are also the most ephemeral, present on a plant for days to weeks. S. taccada flowers studied on the French Polynesian Island of Moorea, for example, remain open for an average of fewer than four days (Liao, 2008), seemingly scant time to recruit microbes from the environment. 
343 Plant microbial distributions over space

344 In microbial biogeography studies, distance between samples is generally a

345 reliable predictor of microbial community dissimilarity, particularly among communities

346 that are not attached to a macro-organism (Martiny et al., 2011; Zinger, Boetius \&

347 Ramette, 2014; Tedersoo et al., 2014), even at the scale of centimeters (Bell, 2010).

348 The distance decay of plant-associated microbial similarity is comparatively less

349 resolved compared with studies of "host-independent" substrates such as ocean, water,

350 or soil. A positive pattern could be attributed to at least two factors and or their

351 cumulative effects. First, dispersal limitation could lead to clinal dissimilarity among

352 communities by enabling "ecological drift" over relatively short timescales (Martiny et al.,

353 2006). Second, geographic distance could correlate with some environmental cline,

354 which selects for a distinct adapted community. Factors such as rainfall (O'Rorke et al.,

355 2017), soil pH (Fierer \& Jackson, 2006), soil nutrients, or even host genotypic clines

356 (Bálint et al., 2013) all contribute to community dissimilarity.

357 Among plant-associated microbes, evidence for the dissimilarity by distance

358 pattern is mixed. Redford and colleagues (2010) found little evidence of geographic

359 structure in pine bacteria phyllosphere communities spanning continents, and Meaden

360 and others (2016) found no evidence for dispersal limitation among Oak phyllosphere

361 bacteria within a 20 ha plot. In contrast, Stone et al. (2000) found strong isolation by

362 distance patterns among Magnolia phyllosphere bacteria located within $400 \mathrm{~m}$ of each

363 other. Oono and colleagues (2017) found that low abundance pine needle fungal 
364 endophytes were spatially structured over $\sim 100 \mathrm{~km}$, but that high abundance 365 communities were not.

In our study, both above-ground and belowground bacteria were correlated with

367

368

369

370

371

372

373

374

375

376

377

378

379

380

381

382

383

384

385

386

387

388 geographic distance (Table 3), although the latter relationship was stronger. Differing community turnover rates among plant parts could be attributable to different dispersal rates since airborne bacteria would presumably travel farther and more quickly due to prevalent trade winds compared to subsurface soil bound communities. Although there were no obvious environmental clines along our transect, microbes may have responded differently to additional unmeasured variables. Multiple studies show that bacteria are particularly sensitive to soil properties such as $\mathrm{pH}$. Substrates change rapidly over short distances from the high tide, and although $\mathrm{pH}$ did not covary in a linear fashion along the transect, $\mathrm{pH}$ was variable among sample sites. For example at a single site for this study, we sampled soils ranging from ph 5.28 to 8.65 (Table S1). Finally, differences in the distance decay relationship could be driven by interactions with the host plant. Obligacy or strong host selection of some community members, for example, could depress turnover if the microbe was required for growth and survival.

\section{Conclusions}

Plant-associated microbes are critical players in plant fitness and health. Our work shows that while both stochastic and deterministic factors play a role in shaping surface phytobiomes, plant part is the most predictive, with nestedness patterns relating strongly to vertical stratification. Bacteria are highly differentiated across a plant, with distance playing a weak, though significant, role in community composition at the scale 
389

390

391

392

393

394 395 396

examined. Despite these patterns, we were unable to describe the majority of community variance in this system. Identifying environmental reservoirs for phytobiomes, particularly those sources for ephemeral reproductive parts, will help in understanding plant associated microbial distributions and the factors that shape them.

\section{Acknowledgements}

The authors wish to thank Michele Langer and Illumina Corporation for their generous support. We also appreciate the assistance and support of Amy Eggers and the Hawai'i Institute of Marine Biology Genetics Core Facility. We also appreciate the feedback of the handling editor and two anonymous reviews. This paper was the result of a class project: High Throughput Sequencing Approaches to Ecology and Evolution at the University of Hawaii at Manoa.

\section{References}

Aleklett K, Hart M, Shade A 2014. The microbial ecology of flowers: an emerging frontier in phyllosphere research. Botany 92:253-266. DOI: 10.1139/cjb-2013-0166.

Almeida-Neto M, Guimaraes P, Guimaraes PR, Loyola RD, Ulrich W 2008. A consistent metric for nestedness analysis in ecological systems: reconciling concept and measurement. Oikos 117:1227-1239. DOI: 10.1111/j.2008.0030-1299.16644.x.

Atmar W, Patterson BD 1993. The measure of order and disorder in the distribution of species in fragmented habitat. Oecologia 96:373-382. DOI: 10.1007/BF00317508.

Baselga A 2010. Partitioning the turnover and nestedness components of beta diversity. Global Ecology and Biogeography 19:134-143. DOI: 10.1007/BF00317469. 
414 Baselga A, Orme CDL 2012. betapart: an R package for the study of beta diversity.

$415 \quad$ Methods in Ecology and Evolution 3:808-812. DOI: 10.2307/1943563.

416 Bálint M, Tiffin P, Hallström B, O’Hara RB, Olson MS, Fankhauser JD, Piepenbring M, 417 Schmitt I 2013. Host genotype shapes the foliar fungal microbiome of balsam poplar 418 (Populus balsamifera). PLoS ONE 8:e53987. DOI: 10.1371/journal.pone.0053987. 419 Bell T 2010. Experimental tests of the bacterial distance-decay relationship. The ISME 420 Journal 4:1357-1365. DOI: 10.1038/ismej.2010.77.

Blüthgen N, Menzel F, Blüthgen N 2006. Measuring specialization in species interaction 422 networks. BMC ecology 6:9. DOI: 10.1186/1472-6785-6-9.

423

424

425

426

427

428

429

430

431

432

433

434

435

436

Bodenhausen N, Horton MW, Bergelson J 2013. Bacterial communities associated with the leaves and the roots of Arabidopsis thaliana. PLoS ONE 8:e56329. DOI: 10.1371/journal.pone.0056329.

Bulgarelli D, Garrido-Oter R, Münch PC, Weiman A, Dröge J, Pan Y, McHardy AC, Schulze-Lefert P 2015. Structure and Function of the Bacterial Root Microbiota in Wild and Domesticated Barley. CHOM 17:392-403. DOI: 10.1016/j.chom.2015.01.011.

Cadotte MW, Cardinale BJ, Oakley TH 2012. Phylogenetic relatedness predicts priority effects in nectar yeast communities. Proceedings of the National Academy of Sciences 105:17012-17017. DOI: 10.1073/pnas.0805962105.

Caporaso JG, Kuczynski J, Stombaugh J, Bittinger K, Bushman FD, Costello EK, Fierer N, Peña AG, Goodrich JK, Gordon JI, Huttley GA, Kelley ST, Knights D, Koenig JE, Ley RE, Lozupone CA, Mcdonald D, Muegge BD, Pirrung M, Reeder J, Sevinsky JR, Turnbaugh PJ, Walters WA, Widmann J, Yatsunenko T, Zaneveld J, Knight R 
437

438

439

440

441

442

443

444

445

446

447

448

449

450

451

452

453

454

455

456

457

458

459

2010. QIIME allows analysis of high-throughput community sequencing data. Nature Methods 7:335-336. DOI: 10.1038/nmeth.f.303.

De Caceres M, Jansen F 2016. Indicspecies: Relationship between Species and Groups of Sites. R package, Version 1.7. 4. 2014.

Fierer N, Jackson RB 2006. The diversity and biogeography of soil bacterial communities. Proceedings of the National Academy of Sciences of the United States of America 103:626-631. DOI: 10.1073/pnas.0507535103.

Fitzpatrick CR, Copeland J, Wang PW, Guttman DS, Kotanen PM, Johnson MTJ 2018. Assembly and ecological function of the root microbiome across angiosperm plant species. Proceedings of the National Academy of Sciences 115:E1157-E1165. DOI: 10.1073/pnas. 1717617115 .

Glick BR 2014. Bacteria with ACC deaminase can promote plant growth and help to feed the world. Microbiological research 169:30-39. DOI:

10.1016/j.micres.2013.09.009.

Hacquard S, Garrido-Oter R, Gonzalez A, Spaepen S, Ackermann G, Lebeis S, McHardy AC, Dangl JL, Knight R, Ley R, Schulze-Lefert P 2015. Microbiota and Host Nutrition across Plant and Animal Kingdoms. Cell host \& microbe 17:603-616. DOI: 10.1016/j.chom.2015.04.009.

Herrera CM, Canto A, Pozo MI, Bazaga P 2010. Inhospitable sweetness: nectar filtering of pollinator-borne inocula leads to impoverished, phylogenetically clustered yeast communities. Proceedings of the Royal Society B: Biological Sciences 277:747754. DOI: 10.1073/pnas.95.12.6578.

Hodgson S, de Cates C, Hodgson J, Morley NJ, Sutton BC, Gange AC 2014. Vertical 

transmission of fungal endophytes is widespread in forbs. Ecology and Evolution 4:1199-1208. DOI: 10.1002/ece3.953.

462 463 464 465 466 467 468 469 470 471 472 473 474 475 476 477 478 479 480 481 communities within individual Ginkgo biloba trees. Environmental Microbiology 482 17:2352-2361. DOI: 10.1111/1462-2920.12695.

Junker RR, Keller A 2015. Microhabitat heterogeneity across leaves and flower organs promotes bacterial diversity. FEMS Microbiology Ecology 91:1-9. DOI:

10.1093/femsec/fiv097.

Junker RR, Loewel C, Gross R, Dötterl S, Keller A, Blüthgen N 2011. Composition of epiphytic bacterial communities differs on petals and leaves. Plant Biology 13:918924. DOI: 10.1111/j.1438-8677.2011.00454.x.

Kennedy PG, Peay KG, Bruns TD 2009. Root tip competition among ectomycorrhizal fungi: Are priority effects a rule or an exception? Ecology 90:2098-2107.

Laforest-Lapointe I, Messier C, Kembel SW 2016. Tree phyllosphere bacterial communities: exploring the magnitude of intra-and inter-individual variation among host species. PeerJ. DOI: 10.7717/peerj.2367/table-3.

Lambais MR, Lucheta AR, Crowley DE 2014. Bacterial Community Assemblages Associated with the Phyllosphere, Dermosphere, and Rhizosphere of Tree Species of the Atlantic Forest are Host Taxon Dependent. Microbial ecology 68:567-574. DOI: 10.1007/s00248-014-0433-2.

Lau JA, Lennon JT 2012. Rapid responses of soil microorganisms improve plant fitness in novel environments. Proceedings of the National Academy of Sciences 109:14058-14062. DOI: 10.1073/pnas.1202319109.

Leff JW, Del Tredici P, Friedman WE, Fierer N 2015. Spatial structuring of bacterial 
483 Leff JW, Lynch RC, Kane NC, Fierer N 2016. Plant domestication and the assembly of 484 bacterial and fungal communities associated with strains of the common sunflower, 485 Helianthus annuus. The New phytologist 214:412-423. DOI:

$486 \quad 10.1023 / \mathrm{A}: 1013343811110$.

487 Liao IT 2008. Pollination biology and reproductive ecology of Scaevola taccada 488 (Goodeniaceae) on Mo'orea, French Polynesia. Biology and Geomorphology of $489 \quad$ Tropical Islands Student Research Papers.

490 Lundberg DS, Lebeis SL, Paredes SH, Yourstone S, Gehring J, Malfatti S, Tremblay J, 491 Engelbrektson A, Kunin V, del Rio TG, Edgar RC, Eickhorst T, Ley RE, Hugenholtz 492 P, Tringe SG, Dangl JL 2012. Defining the core Arabidopsis thaliana root 493 microbiome. Nature 488:86-90. DOI: 10.1038/nature11237.

494 Martiny JBH, Bohannan BJM, Brown JH, Colwell RK, Fuhrman JA, Green JL, Horner495 Devine MC, Kane M, Krumins JA, Kuske CR, Morin PJ, Naeem S, s LOVA, 496 Reysenbach A-L, Smith VH, Staley JT 2006. Microbial biogeography: putting 497 microorganisms on the map. Nature reviews. Microbiology 4:102-112. DOI: 498 doi:10.1038/nrmicro1341.

499 Martiny JBH, Eisen JA, Penn K, Allison SD, Horner-Devine MC 2011. Drivers of 500 bacterial beta-diversity depend on spatial scale. Proceedings of the National 501 Academy of Sciences 108:7850-7854. DOI: 10.1073/pnas.1016308108.

502 Meaden S, Metcalf CJE, Koskella B 2016. The effects of host age and spatial location 503 on bacterial community composition in the English Oak tree ( Quercus robur). 504 Environmental Microbiology Reports 8:649-658. DOI: 10.1128/AEM.02294-08. 505 Müller DB, Vogel C, Bai Y, Vorholt JA 2016. The Plant Microbiota: Systems-Level 

Insights and Perspectives. Annual review of genetics 50:211-234. DOI:

507 10.1146/annurev-genet-120215-034952.

508

O'Rorke R, Cobian GM, Holland BS, Price MR, Costello V, Amend AS 2015. Dining local: the microbial diet of a snail that grazes microbial communities is geographically structured. Environmental Microbiology 17:1753-1764. DOI: 10.1111/1462-2920.12630.

O'Rorke R, Tooman L, Gaughen K, Holland BS, Amend AS 2017. Not just browsing: an animal that grazes phyllosphere microbes facilitates community heterogeneity. Proceedings of the National Academy of Sciences 109:13022-13027. DOI: 10.1073/pnas.1209872109.

516 Oksanen J, Blanchet FG, Kindt R, Legendre P, Minchin PR, O'Hara RB, Simpson GL, 517 Solymos P, Stevens MHH, Wagner HL 2013. vegan: community Ecology Package. 518 R package version 2.0-7. Community ecology package Version, 2, 0-7.

519 Oono R, Rasmussen A, Lefèvre E 2017. Distance decay relationships in foliar fungal 520 endophytes are driven by rare taxa. Environmental Microbiology 19:2794-2805. 521 DOI: 10.1111/1462-2920.13799.

522 Ottesen AR, Peña AG, White JR, Pettengill JB, Li C, Allard S, Rideout S, Allard M, Hill 523 T, Evans P, Strain E, Musser S, Knight R, Brown E 2013. Baseline survey of the 524 525 526 anatomical microbial ecology of an important food plant: Solanum lycopersicum (tomato). BMC Microbiology 13:114. DOI: 10.1186/1471-2180-13-114.

Panke-Buisse K, Poole AC, Goodrich JK, Ley RE, Kao-Kniffin J 2015. Selection on soil microbiomes reveals reproducible impacts on plant function. The ISME Journal 9:980-989. DOI: 10.1038/ismej.2014.196. 
529 Peay KG, Schubert MG, Nguyen NH, Bruns TD 2012. Measuring ectomycorrhizal fungal 530 dispersal: macroecological patterns driven by microscopic propagules. Molecular $531 \quad$ Ecology 21:4122-4136. DOI: 10.1111/j.1365-294X.2012.05666.x.

532 Peay K, Bruns T, Kennedy P 2007. A strong species-area relationship for eukaryotic 533 soil microbes: island size matters for ectomycorrhizal fungi. Ecology.

534 Redford AJ, Bowers RM, Knight R, Linhart Y, Fierer N 2010. The ecology of the 535 phyllosphere: geographic and phylogenetic variability in the distribution of bacteria 536 on tree leaves. Environmental Microbiology 12:2885-2893. DOI: 10.1111/j.1462$537 \quad 2920.2010 .02258 . x$.

538 Remus-Emsermann MNP, Schlechter RO 2018. Phyllosphere microbiology: at the 539 interface between microbial individuals and the plant host. The New phytologist 540

541 Rognes T, Flouri T, Nichols B, Quince C, Mahé F 2016. VSEARCH: a versatile open 542 source tool for metagenomics. PeerJ 4:e2584. DOI: 10.7717/peerj.2584.

543 Si X, Baselga A, Leprieur F, Song X, Ding P 2016. Selective extinction drives taxonomic 544 and functional alpha and beta diversities in island bird assemblages. Journal of $545 \quad$ Animal Ecology 85:409-418. DOI: 10.1126/science.1083312.

546 Soininen, J., Heino, J., \& Wang, J. (2018). A meta-analysis of nestedness and turnover 547 components of beta diversity across organisms and ecosystems. Global Ecology $548 \quad$ and Biogeography, 27(1), 96-109.

549 Sonnenburg ED, Smits SA, Tikhonov M, Higginbottom SK, Wingreen NS, Sonnenburg $550 \mathrm{JL}$ 2016. Diet-induced extinctions in the gut microbiota compound over generations. $551 \quad$ Nature 529:212-215. DOI: 10.1038/nature16504. 
552 Stone JK, Bacon CW, White JF 2000. An overview of endophytic microbes:

553 endophytism defined. Microbial endophytes 3:29-33.

554 Tedersoo L, Bahram M, PÕLME S, Kõljalg U, Yorou NS, Wijesundera R, Villarreal Ruiz

555 L, Vasco-Palacios AM, Thu PQ, Suija A, SMITH ME, Sharp C, Saluveer E, Saitta A,

556 Rosas M, Riit T, Ratkowsky D, Pritsch K, Põldmaa K, Piepenbring M, Phosri C,

557 Peterson M, Parts K, Pärtel K, Otsing E, NOUHRA E, Njouonkou AL, Nilsson RH,

558 Morgado LN, Mayor J, May TW, Majuakim L, Lodge DJ, Lee SS, Larsson K-H,

559 Kohout P, Hosaka K, Hiiesalu I, HENKEL TW, Harend H, Guo L-D, Greslebin A,

560 Grelet G, Geml J, Gates G, Dunstan W, Dunk C, Drenkhan R, Dearnaley J, De

561 Kesel A, Dang T, Chen X, Buegger F, Brearley FQ, Bonito G, Anslan S, Abell S,

562 Abarenkov K 2014. Fungal biogeography. Global diversity and geography of soil

563 fungi. Science 346:1256688. DOI: 10.1126/science.1256688.

564 Thompson LR, Sanders JG, Mcdonald D, Amir A, Ladau J, Locey KJ, Prill RJ, Tripathi

565 A, Gibbons SM, Ackermann G, Navas-Molina JA, Janssen S, Kopylova E, Vázquez-

566 Baeza Y, Gonzalez A, Morton JT, Mirarab S, Zech Xu Z, Jiang L, Haroon MF,

567 Kanbar J, Zhu Q, Jin Song S, Kosciolek T, Bokulich NA, Lefler J, Brislawn CJ,

568 Humphrey G, Owens SM, Hampton-Marcell J, Berg-Lyons D, McKenzie V, Fierer N,

569 Fuhrman JA, Clauset A, Stevens RL, Shade A, Pollard KS, Goodwin KD, Jansson

570 JK, Gilbert JA, Knight R, Earth Microbiome Project Consortium 2017. A communal

571 catalogue reveals Earth's multiscale microbial diversity. Nature 551:457-463. DOI:

$572 \quad 10.1038 /$ nature24621.

573 Weiss S, Xu ZZ, Peddada S, Amir A, Bittinger K, Gonzalez A, Lozupone C, Zaneveld

574 JR, Vázquez-Baeza Y, Birmingham A, Hyde ER, Knight R 2017. Normalization and 
575 microbial differential abundance strategies depend upon data characteristics. 5:27.

576 DOI: 10.1186/s40168-017-0237-y.

577 Zinger L, Boetius A, Ramette A 2014. Bacterial taxa-area and distance-decay

578 relationships in marine environments. Molecular Ecology 23:954-964. DOI:

$579 \quad 10.1111 / \mathrm{mec} .12640$. 


\section{Figure 1}

Each sampling location indicates where seven biological samples were collected (six plant parts and a soil sample).

Sites were spaced ca. $6 \mathrm{~km}$ along the windward coast. Ten sites were sampled in Kailua (inset). Axes represent decimal degrees. Topography is show to indicate that all samples were collected at sea level and with a similar aspect.

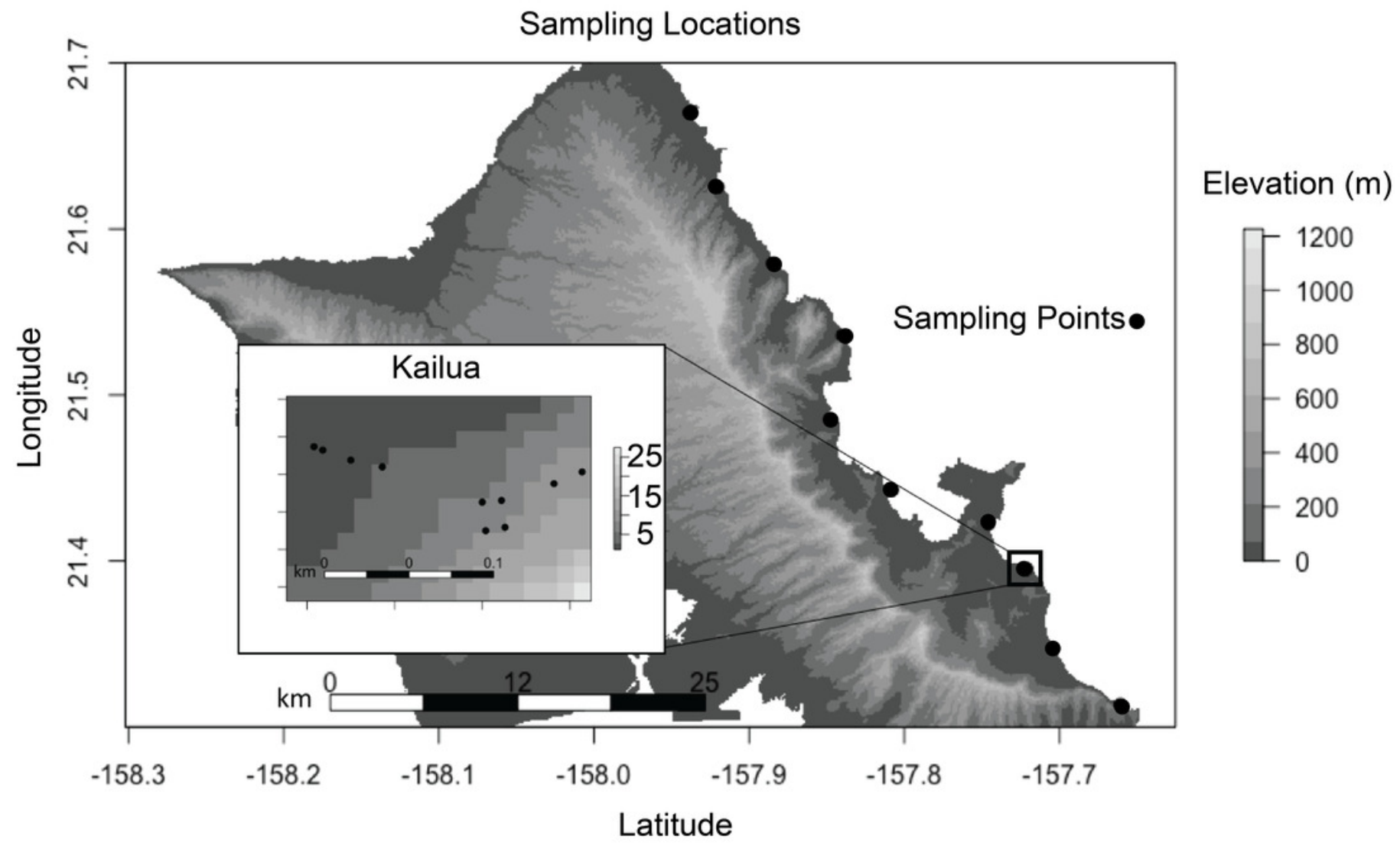


Figure 2 (on next page)

Nestedness plot of bacteria aggregated by plant part.

Presence of an OTU in a plant part is represented as a rectangle. OTUs are ordered by occupancy (left to right) across plant parts, and rows are ordered by highest OTU richness (top to bottom). If all OTUs occurred above the "Fill line" (curved line), the network would be perfectly nested. 


\section{Figure 3 (on next page)}

Non-metric multidimensional scaling plots of microbial communities colored by habitat.

Ellipses indicate $95 \%$ confidence intervals. Above and below-ground parts are differentiated along the first axis, with leaves intermediate. 


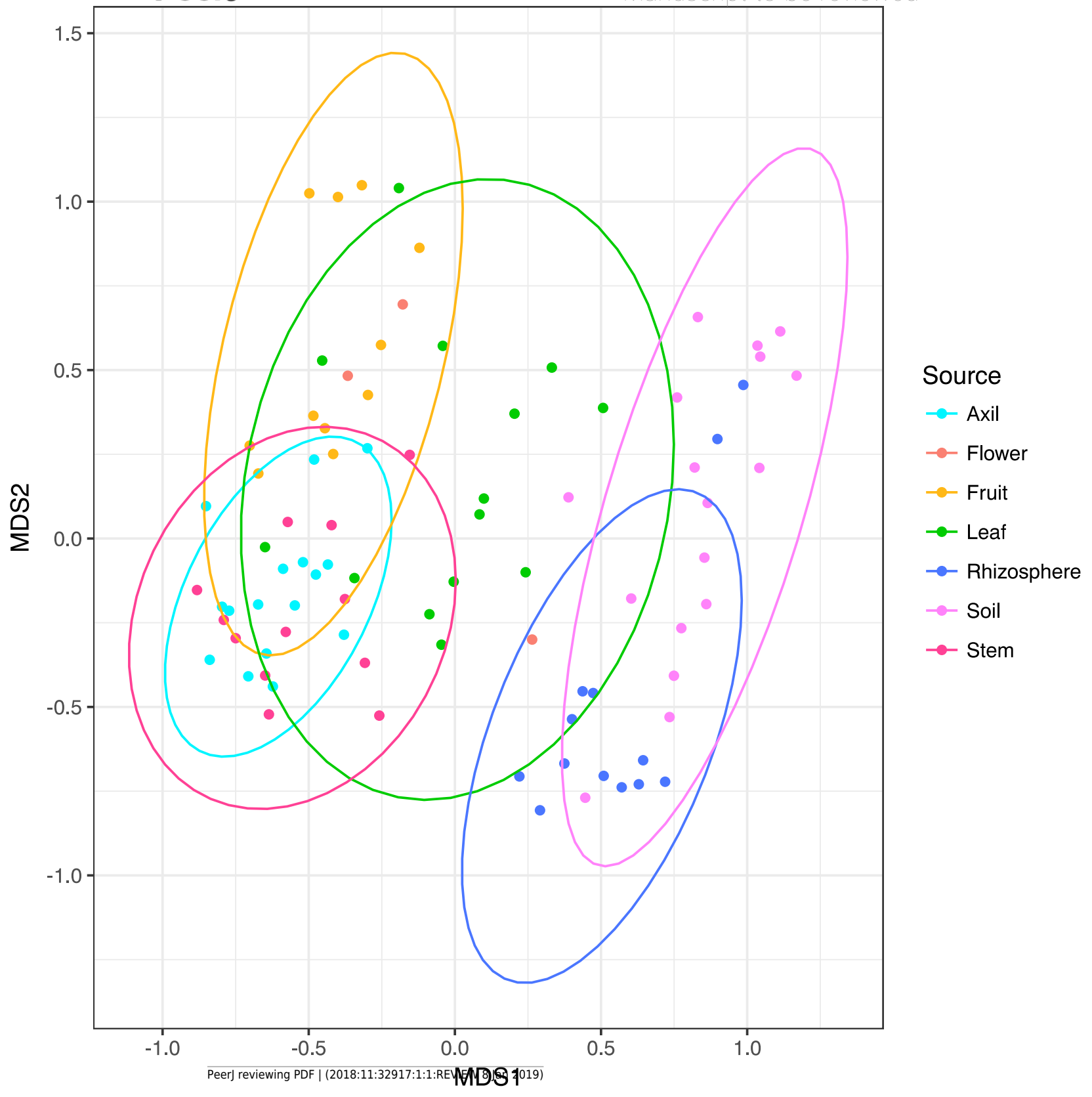




\section{Figure 4}

Heatmap of order-level taxa as distributed across plant parts.

Cell values are calculated proportionally across samples (rows). 
Proportional Abundance

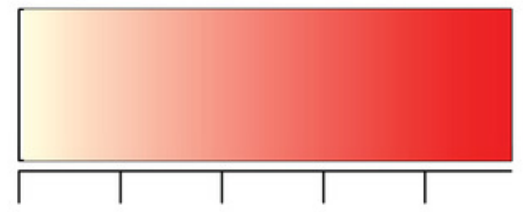

$0 \quad 0.20 .40 .60 .8$
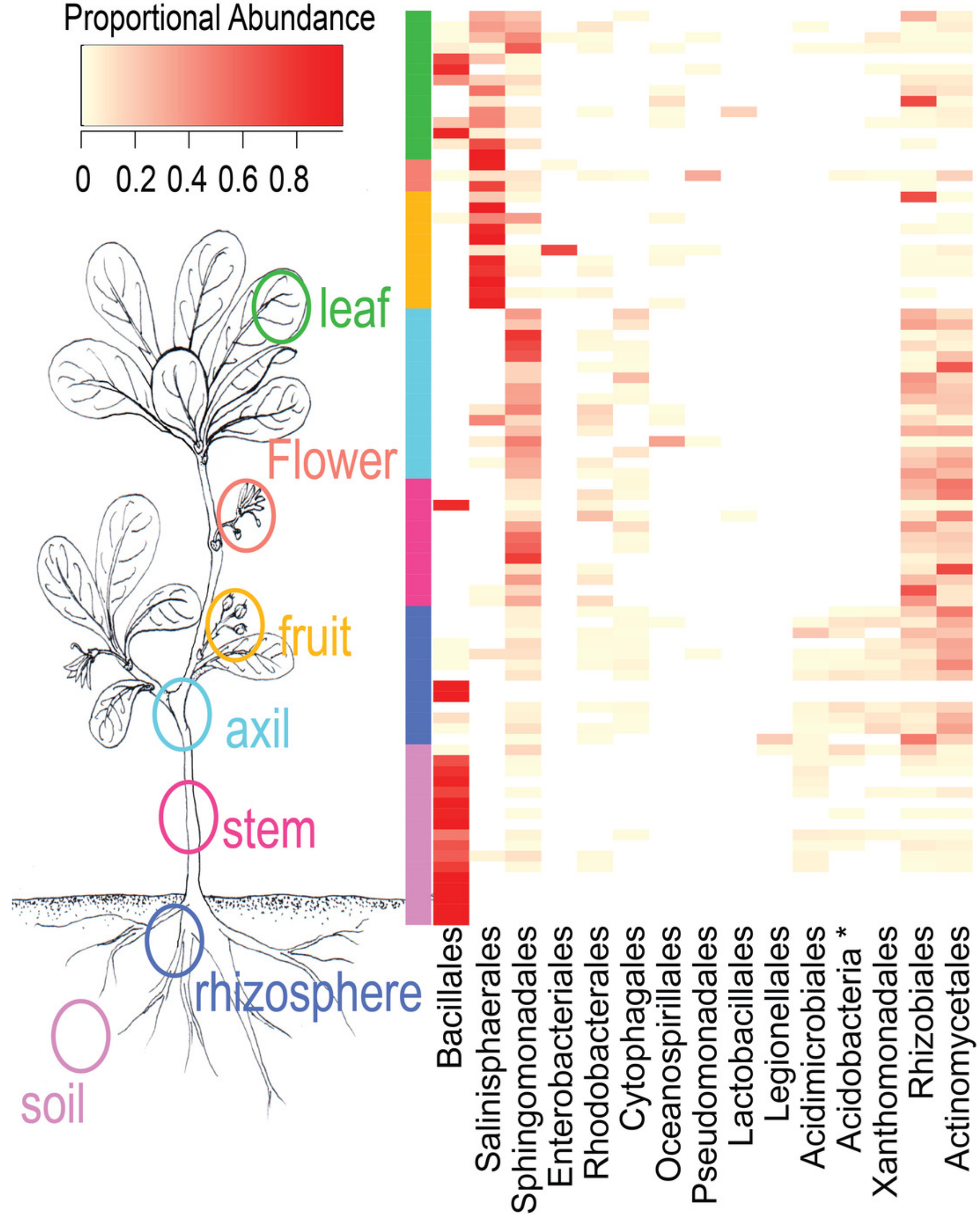


\section{Table $\mathbf{1}$ (on next page)}

Network stucture of microbial communities.

The $d^{\prime}$ statistic is a measure of specialization by habitat ranging from 0 (not specialized) to 1 (completely specialized). $\mathrm{H} 2$ is an index of specialization across all taxa within the network and is measured on the same scale. Both networks were significantly more specialized than randomized null simulations would predict. Plant parts are ordered by nestedness structure, with the most species-rich communities on the top. Turnover and nestedness proportions describe community dissimilarity among plant parts explained by that process 
Table 1 Network stucture of microbial communities. The d' statistic is a measure of specialization by habitat ranging from 0 (not specialized) to 1 (completely specialized). $\mathrm{H} 2$ is an index of specialization across all taxa within the network and is measured on the same scale. Both networks were significantly more specialized than randomized null simulations would predict. Plant parts are ordered by nestedness structure, with the most species-rich communities on the top. Turnover and nestedness proportions describe community dissimilarity among plant parts explained by that process.

\begin{tabular}{|c|c|c|}
\hline Sample & $d^{\prime}$ & $P$ \\
\hline Rhizosphere & 0.47 & 0.001 \\
\hline Soil & 0.55 & 0.001 \\
\hline Leaf & 0.29 & 0.001 \\
\hline Axil & 0.31 & 0.001 \\
\hline Stem & 0.34 & 0.001 \\
\hline Flower & 0.25 & 0.001 \\
\hline Fruit & 0.30 & 0.001 \\
\hline Nestedness Temp. & 28.21 & 0.001 \\
\hline NODF & 0.24 & 0.001 \\
\hline $\mathrm{H} 2$ & 0.64 & 0.001 \\
\hline Turnover & 0.84 & \\
\hline Nestedness & 0.09 & \\
\hline
\end{tabular}


Table 2 (on next page)

PERMANOVA examining community compositional variance explained by plant part, site, or their interaction. 
Table 2 PERMANOVA examining community compositional variance explained by plant part, site, or their interaction.

\begin{tabular}{rrrrrr} 
Component & \multicolumn{2}{c}{$\begin{array}{c}\text { Degrees } \\
\text { Freedom }\end{array}$} & $\begin{array}{c}\text { Sum of } \\
\text { Squares }\end{array}$ & \multicolumn{1}{c}{$F$} & \multicolumn{1}{c}{$P$} \\
\hline Part & 6 & 5.1887 & 5.8391 & $\mathbf{0 . 0 0 1}$ \\
Site & 8 & 2.894 & 2.4426 & $\mathbf{0 . 0 0 1}$ \\
Part:Site & 29 & 6.6346 & 1.5447 & $\mathbf{0 . 0 1 2}$ \\
Residual & 4 & 0.5924 & &
\end{tabular}

1 


\section{Table 3(on next page)}

Mantel tests measure the correlation between geographic distance and microbial community dissimilarity for Scaevola taccada surface microbes. 
Table 3 Mantel testsmeasure the correlation between geographic distance and microbial community dissimilarity for Scaevola taccada surface microbes. Sample sites occur as 10 locations spanning $60 \mathrm{~km}$ on the island of Oahu, HI. Mantel's statistic measure Pearson's product-moment correlation with 999 permutations. Significant values indicating a relationship between spatial distance and community dissimilarity are bolded. In this analysis a single plant individual was selected from the Kailua site. Above-ground refers to all plant parts, whereas belowground refers to rhizospere and soil.

\begin{tabular}{lrrr}
\hline Plant part & r-value & p-value & $n$ \\
\hline All plant parts & 0.06538 & $\mathbf{0 . 0 4 6}$ & 48 \\
Above-ground & 0.1319 & $\mathbf{0 . 0 1 7}$ & 32 \\
Below-ground & 0.3781 & $\mathbf{0 . 0 0 8}$ & 16 \\
Soil & 0.1334 & 0.231 & 9
\end{tabular}

